\title{
The importance of the instrumental factor and its role in translation a text from Russian to Arabic and Arabic to Russian
}

\author{
Lecturer. Abbas Abdulameer Shahadha \\ Basic education college / university of Wasit \\ abbasabed1974@gmail.com \\ 07816030516
}

Abstract:

The research focuses on the concept of instrumentalism and what it means in linguistics, it is not limited to the concept of meanings of the units or symbols of the language, but addresses all the issues related to the understanding of participants in the process of communication, and addresses the treatment of these issues according to the experience of people language and non-language, which surrounds the process of linguistic communication, And attitudes and contributors to verbal action, and dealt with the role of a successful translator who can be familiar with all issues related to the understanding of participants, which include text, context and denominator.

اهمية العامل الذرائعي ودوره في ترجمة النص من الروسية العربية ومن

$$
\begin{aligned}
& \text { العربية الى الكو سية } \\
& \text { المدرس عباس عبد الامير شحاذة }
\end{aligned}
$$

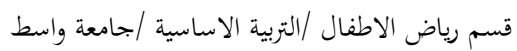

$$
\begin{aligned}
& \text { abbasabed1974@gmail.com } \\
& 07816030516
\end{aligned}
$$

يركز البحث على مفهوم الذرائعية وما يعنيه في علم اللغة، فهو لا يقتصر على مفهوم المعاني للوحدات او الرموز اللغوية ، بل يتناول كل المسائل المتعلقة بفهم المشتركين في عملية الاتصال ، كما يتناول معالجة هذه المسائل وفقا لخبرة الاشخاص اللغوية وغي اللغوية ،التي تحيط بعملية الاتصال

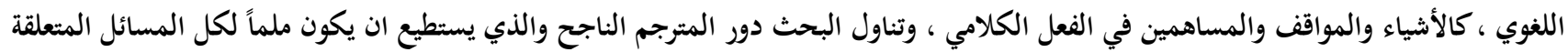
بفهم المشتركين والتي تتشمل على النص والسياق والمقام.

\section{Важность инструментального фактора и его роль в переводе текста с русского на арабский и наоборот}

Соискатель

Аббас Абдульамир шхада 
Введение;

Тема нашего исследования носит называние (Важность инструментального фактора и его роль в переводе текста с русского на арабский и наоборот). После завершения исследования (Семантические эквивалентны) мы начали писать это исследование, в котором мы подчеркиваем роль переводчика в процессе перевода информации с языка оригинала на язык перевода и знания всех вовлеченных в этот процесс. При переводе переводчик должен учитывать инструментальный фактор, и хорошее знание предметов и ситуаций, описанных в оригинальном тексте, т.е. неязыковые знания.

В ряде случаев переводчик должен комментировать и интерпретировать, чтобы объяснить любые культурные и социальные области, понятные говорящему на языке оригинала, неизвестном говорящему на языке перевода. Например, в пьесе Антона Чехова "Вишневый сад" Евиходов спрашивает собеседника .

((Ты читал Бокель ? )) . Переводчик прокомментировал слово «Бокель» в арабском переводе этого места из текста Генри Томаса Боклья, историка и английского социолога.

Инструментальным значением является связь между символом и человеком. И более точно между символом и людьми, которые его используют. Концепция инструментализма не ограничивается лингвистикой и в более широком смысле наукой о символах. О понятии значений языковых единиц (символы вообще). Эта концепция намного шире, она касается всех вопросов, связанных с пониманием участников, - в процессе коммуникации- любых лингвистических единиц и словесного вывода и решения этих вопросов в соответствии с лингвистическим и неязыковым опытом людей , участвующих в процессе коммуникации. Таким образом, «(инстинктивный)) в этом смысле градуировался, вне смысла значений символов и даже за пределами общих вопросов лингвистики в целом, на основе изучения нелингвистических факторов речи, таких как вещи и отношения, а также вкладчики в словесное действие. Мы не можем говорить о значении значений, за исключением случаев, когда связь членов лингвистического сообщества с символами языка становится частью символической структуры самого символа, т. Е. Фиксируется постоянно.

\section{1. Инструментализм}

Инструментализм в философии науки прежде всего связан с трактовкой научных теорий как средстворгани зации научных суждений во взаимосвязанные логическ ие структуры, где одни высказывания выводятсяиз дру гих по установленным правилам; теории ничего не опи сывают и не объясняют, они нужны только длярешени я практических (конструктивных, вычислительных, из мерительных и т. п.) проблем научногоисследования. К. Попперсчитал, что инструментализм несовместим с “оценкой науки как одного из величайших достижений человеческого духа” (Поппер М., 1983).

2. Правовое учение Дж. Дьюи
(инструментализм)

Джон Дьюи (1859 - 1952) - американский философ и педагог, представитель философского направления прагматизм. Автор более 30 книг и 900 научных статей по философии, социологии, педагогике и др. дисциплинам. Дьюи развил новый вариант прагматизма - инструментализм, разработал прагматистскую методологию в области логики и теории познания.

Форматы перевода слов с одного языка на другой

Л.С. Бархударов выделяет два основных типа речи: обиходно-разговорную и книжнописьменную. В пределах последней различаются следующие основные жанры: художественная литература, официально-научный жанр и публицистический жанр (Бархударов, 1975)

Есть две формы для передачи или перевода слова:: обычную модель и написанную письменную модель. В написанно-редакционной модели рассматриваются следующие основные типы :-

1- Научно - официальная формула

\section{2- Литературно-социальная формула}

\section{3- Литературная формула}

Форматы перевода слов является одной из проблем перевода с русского на арабский и с арабского на русский .

Эмоциональная формула слова - одна из проблем перевода на русском и арабском языках

Каждый вид подразделяется на различные виды. Таким образом, мы различаем в литературном жанре: художественную прозу, театральное искусство, поэзию и различаем в научно-формальном виде: официальные рабочие тексты, медиа-журналистские скандалы, документальные фильмы, научно-технические тексты, Социальные, социальные и литературные тексты и риторика.

Форматы перевода слов может включать следующие типы ;-

А) Умеренно нейтральная формула

Нейтральная лексика предназначена для констатирующего, безоценочного, нетерминологического обозначения предметов, 
понятий повседневной жизни, явлений природы, периодов жизни человека и состояний его жизнедеятельности, отрезков времени и т.п. Она лишена экспрессии, эмоциональных и социальных оценок (Большая Российская энциклопедия, 1997). Нейтральная формула касается слов, используемых во всех формах и типах речи, т. е. Не-риторических словах. Большинство слов, которые включены в словарь любого языка, относятся к нейтральному описанию

Нейтральная лексика - это слова, не прикрепленные к определенному стилю речи, имеющие стилистические синонимы (книжные, разговорные, просторечные), на фоне которых они лишены стилистической окраски (Розенталь, Теленкова, 1976)

В) Обычная формула

Эта формула относится к словам, используемым в устной речи и в (неформальной) ситуации

Смотрите следующие русские слова :-

\begin{tabular}{|c|c|}
\hline электричка & قطار كهربائي \\
\hline раздевалка & غرفة لبس ، مشلح \\
\hline влипнуть & تورط ، ارتطم \\
\hline щлепнуться & هوى ، وقِ \\
\hline тренкать & عرقه \\
\hline чудной & غريب ، شاذ \\
\hline
\end{tabular}

смотрите на общие арабские слова :-

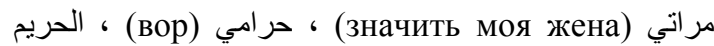
(туалет) بمنى (женщины) بيت الادي (зبر)

\section{C - Письменная формула}

Эта формула относится к словам, используемым в письменной речи, и хотя эти слова могут использоваться в (формальной) позиции и в устной речи, они не используются в народном языке..

Смотрите следующие русские слова:-

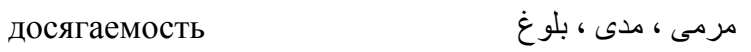

$$
\begin{aligned}
& \text { الآنف الذكر، المار ذكرهالمذكور اعلاه } \\
& \text { выщеупомянутый }
\end{aligned}
$$

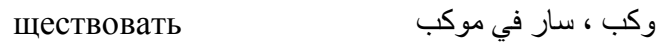

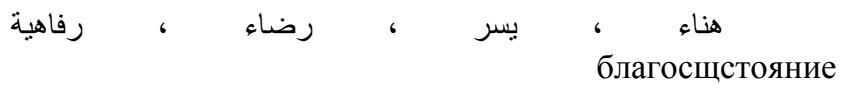

Смотрите общие арабские слова:-

$$
\text { عقلته ، ، حرمه ، }
$$

$$
\text { زوجته ، حامل (بمعنى حبلى) }
$$

(Г) поэтическая формула
Эта формула касается слов, наиболее часто используемых на языке поэзии:

$$
\begin{aligned}
& \text { Смотрите следующие русские слова: - } \\
& \text { отчиза وطن ، بلد آباء }
\end{aligned}
$$

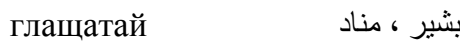

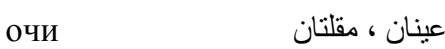

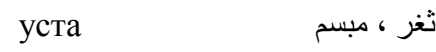

Смотрите следующие арабские

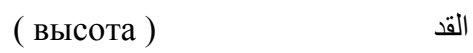

длинные волосы

$$
\text { الفرع }
$$

(черные) )

Пухлый хромой )

$$
\text { الوجي }
$$

( бык

$$
\begin{aligned}
& \text { ( Мягкая девушка) الرملودة } \\
& \text { красивая ) }
\end{aligned}
$$

женщина(полная)

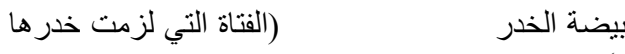

$$
\begin{aligned}
& \text { لاتخرج منه ) }
\end{aligned}
$$

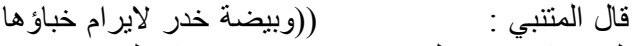

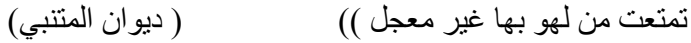

$$
\begin{aligned}
& \text { الجؤذر }
\end{aligned}
$$

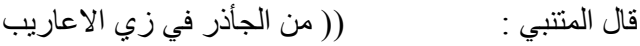

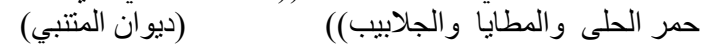

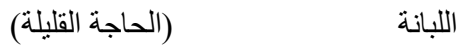

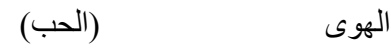

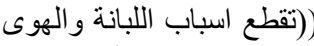

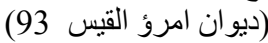

$$
\begin{aligned}
& \text { قال أمرؤ القيس }
\end{aligned}
$$

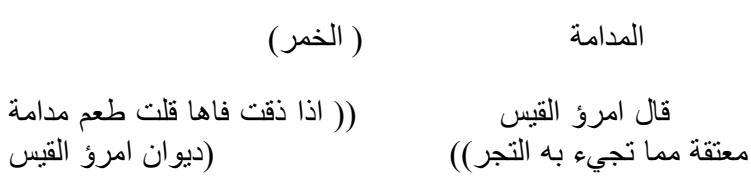

Д- Официальные слова и термины

Эта формула касается слов, используемых в научно-формальном жанре. Все научные и технические термины относятся к этому описанию, и мы должны также приписать ему специальные термины и слова, используемые в областях государства, права, экономики, финансов, военных действий, социальной и политической жизни и административной работы.

Часто одно нейтральное слово имеет несколько экспрессивных синонимов, различающихся по степени эмоционального напряжения. Яркая экспрессия выделяет слова 
торжественные, риторические, поэтические. Особая экспрессия отличает слова шутливые, иронические, фамильярные. Экспрессивные оттенки разграничивают слова неодобрительные, пренебрежительные, презрительные, уничижительные, вульгарные, бранные (Голуб, 1999) .

\section{3. Качества слова}

Качества слова - уровень, который слово достигает с точки зрения формальной или неформальной степени. Следует учитывать ситуацию, которая требует выбора любого языка, в том числе лексических единиц. Такое отношение определяется, во-первых, статус участников процесса общения, будь то знакомые, родственники, известные люди или люди с высоким социальным статусом .

. Во-вторых, качества слова определяется условиями, в которых происходит процесс общения, поскольку человек не говорит на собрании, на официальном положении или на службе, говорит в домашней положении , даже со своими близкими друзьями и родственниками.

Мы можем различить - по языку - качества следующих русских слов:

А- бесценные русские слова

$\begin{array}{lr}\text { оболтус } & \text { خبيث } \\ \text { парщтвец } & \text { пبيث بثدة }\end{array}$

Б- Общие средные русские слова . авоська حقيبة

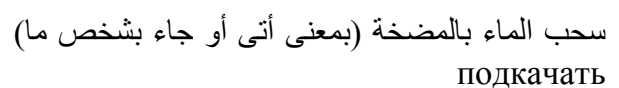

подвыпивщий

$$
\text { ثمل قليلا }
$$

В- Русские формальные слова.

$$
\begin{aligned}
& \text { прибыть } \\
& \text { отчислить } \\
& \text { وصل ، قدم } \\
& \text { طرح ، حسم ، تمد } \\
& \text { دوري } \\
& \text { زواج }
\end{aligned}
$$

(C) Русские слова высокого уровня

$$
\begin{aligned}
\text { с } \\
\text { вкезя } \\
\text { вкить } \\
\\
\\
\text { лицезреть }
\end{aligned}
$$

Следует отметить, что во многих случаях язык содержит слова сходного семантического значения, которые обусловлены различными качествами, например :

$$
\begin{array}{cc}
\text { : } & \text { Дрыхнуть } \\
\text { : } & \text { (бесценные слова) } \\
\text { : } & \text { спать }
\end{array}
$$

(натуральные слова (нейтральность))

( формальные слова) حاسر : اسر : отдыхать

( слова высокого уровня ) : Пан : Почивать

Большинство слов происходит из-за нейтрального качества, слова могут использоваться в любом типе качества слова, а нейтральные слова могут использоваться красноречиво в любой форме речи.

Эмоциональная форма слова

Понятия эмоциональные слова не содержат оценки; в то же время слова, в которых оценка составляет само их лексическое значение (причем оценка не эмоциональная, а интеллектуальная), не относятся к эмоциональной лексике (Голуб, 1999). Эмоциональное отношение говорящего к объектам, явлениям, действиям и феноменам, которые обозначены конкретными словами и фразами на любом языке, является компонентом его семантической структуры. В этом случае можно говорить об эмоциональной форме слова, то есть о негативной или позитивной оценке вещи или понятия, Который указывает это слово. Слова, которые не включают в себя ни одного случая оценки, считаются «нейтральноэмоциональными». Таким образом, лексические единицы можно разделить на три основные категории: негативные эмоциональные слова, позитивные эмоциональные слова и нейтральные эмоциональные слова.

Примеры негативной эмоциональной формы следующие русские слова:-

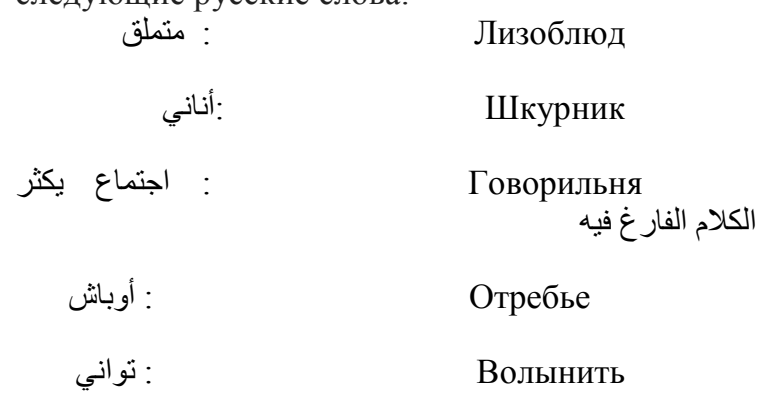

Эмоциональные негативные русские слова формулируются путем догоняющего, то есть путем добавления так называемых уничижительных суффиксов.

Например:

человечищко , избенка, городищко

Слова, имеющие положительную эмоциональную форму, формулируются на русском языке путем добавления так называемых прилагательных (ласкательные) к нейтральным 
эмоциональным словам. Смотрите следующие слова :лесик, дружочик, сестичка, братец

Следует отметить, что нейтральные и ненейтральные символы могут существовать для одного семантического значения. Обратите внимание на следующие русские слова: -

$$
\text { : } \quad \text { : } \quad \text { Мятеж }
$$

(эмоциональное нейтральное слово )

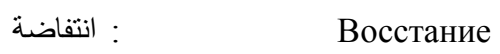

.(эмоциональное нейтральное слово)

$$
\text { جاسوس }
$$

\section{.( Отрицательное эмоциональное слово )}

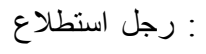

Разведчик

.(эмоциональное нейтральное слово)

4- стилистическое описание .

В составе книжной лексики можно выделить слова, свойственные книжной речи в целом, и слова, закрепленные за конкретными функциональными стилями. Функциональная закрепленность лексики наиболее определенно выявляется в речи. Книжные слова не подходят для непринужденной беседы, научные термины нельзя употребить в разговоре с ребенком, разговорные и просторечные слова неуместны в официально-деловом стиле. Возможность использовать слово в любом стиле речи свидетельствует о его общеупотребительности (Голуб, 1999). Разумеется, классификация лексики по стилистическому описанию, качеству слов и эмоциональной форме очень упрощена, Это не отражает много отношений между словами с точки зрения их инструментальных значений. Более того, в некоторых случаях сложно определить, к каким инструментальным типом следует отнести описание слова или фразы. Часто используемые описательные слова часто упоминаются как бесценное качество, естественное качество (нейтральное) и слова стилистического описания к формальному качеству, И слова поэтического описания к высокому качеству. Таким образом мы замечаем тесную связь между стилистическим описанием и качествами слов и эмоциональной окраской. Негативные эмоциональные слова часто приписывают бесценному качеству, но позитивные эмоциональные слова относятся к высокому качеству, к поэтической лексике и так далее.

Следует иметь в виду, что в некоторых случаях одно слово часто имеет стилистическое описание, конкретное качество или эмоциональную форму. Например, русское слово (конь), что означает «و جو "حصان ، فرس, используется, как поэтическое слово, а также русское слово «гласит». (قال ، نصان), они относятся к высокому качеству и формальному качеству.

Например:параграф третий гласит (تنص الفقرة الثالثة )

Слова, которые имеют суффикс ((клевета)), которые имеют эмоциональную форму в определенных контекстах, Может принимать характер нежности, означает положительный эмоциональный характер. Это указывает на то, что реальные отношения сложны между различными типами инструментальных значений и категориями лексикологического словаря, которые различаются и определяются на основе этих значений.

Мы чувствуем связь слов-терминов с научным языком, относим к публицистическому стилю слова, связанные с политической тематикой, выделяем как официально-деловые слова, употребляемые в делопроизводстве" (Голуб, 1999). Итак, помимо трех основных типов инструментального значения, стилистического описания, типа слов и эмоциональной окраски, четвертый тип значения может быть приписан инструментальному значению((Коммуникационная нагрузка)) лингвистических элементов системы предложений или (синтаксис информации в предложении. ). Понятно, что система предложений состоит, с одной стороны, из лингвистических элементов, содержащих информацию, ранее известную читателю или слушателю, используемую автором или говорящим в качестве элементов информации при создании сообщения, и состоящую, с другой стороны, из лингвистических элементов, содержащих новую информацию, неизвестную читателю или слушатель

Известно, что каждое предложение содержит прямую и подходящую идею. Идея предложения основана на актере, психологе, на фразе «Кто живет в стеклянном доме, не должен бросать камни в людей». Первый раздел - это идея (Кто живет в стеклянном доме). Второй раздел - По мере необходимости (не должен бросать камни в людей).

Состав идеи в предложении может выглядеть по-другому («Состав информации в предложении»). Это связано с порядком текста в виде двух понятий, а именно («навязанный») и («новый»), который обычно называют предметом и комментарием. Это требует, чтобы идея была связана с тем, что навязано, и чтобы реальность была связана с новым.

В примере (Я дал Мухаммеду пальто), (Мухаммед) навязанный - и ((пальто)) является новым.

В примере ((я дал пальто Мухаммеду)), навязанный ((пальто)), а новый - ((Мухаммед)). Таким образом, ясно, что изменение в составе предложения может иметь значение между тем, что навязывается, и тем, что является новым.

В русском предложении ((Иванов пришел)) слово «Иванов» навязыванный, а слово «пришел» является новым, и если мы изменим порядок слов, состав информации в предложении изменится. Пришел Иванов слово ((пришел)) навязыванное и известное, а слово (Иванов) является новым. Читатель или слушатель в первом случае знает, что речь идет об 
определенном человеке по имени (Иванов) и этот человек известный . Во втором случае читатель или слушатель знает, что пришел человек по имени «Иванов», но не знает точно, кто этот человек.

Поскольку «коммуникативноя полнота» или «состав информации в предложении» определяется контекстуальными факторами и словестной позиции, перевод значений слов требует от переводчика анализа контекста и положения, в котором они появляются, даже если они не были лингвистическими.

. Правильная передача коммуникативной полноты является необходимым условием эквивалентности перевода. Однако этот тип значения характеризуется в принципе_всеми другими типами, что на самом деле (грамматический), Потому что этот тип имеет дело не c некоторыми лингвистическими символами, а с полными фразами.

Следует отметить, что изменение инструментального значения . При сравнении лексических единиц разных языков больше, чем различий семантических значений. Особенностью эмоционально-оценочной лексики является то, что эмоциональная окраска "накладывается" на лексическое значение слова, но не сводится к нему, функция чисто номинативная осложняется здесь оценочностью, отношением говорящего к называемому явлению (Голуб, 1999).

Кажется, что ситуация естественна, когда две единицы двух языков совпадают с точки зрения семантических значений и различаются с точки зрения их инструментальных значений, то есть с точки зрения стилистического описания или типов слов или эмоциональной окраски.

Разница в инструментальных значениях единиц двух лексических языков очевидна при сравнении групп слов или «синонимов». Взять, к примеру, следующие синонимичные русские слова: Недруг неприятель противник враг)

Все эти слова, кроме слова ( недруг), имеют два смысловых значения: -

1- Человек, который относится к кому-то или чему-то с враждой.

2. Силы контрагента.

Слово «недруг» имеет только первое значение, в отличие от слова «противник»), что также означает (участник спортивного матча против кого-нибудь). Что касается инструментального значения этих слов, его можно определить следующим образом:

Враг : Нейтральное слово с точки зрения стилистического описания, осознанности и эмоциональной окраски.

Противник : Нейтральное слово, а также специальный военный термин, в смысле сил противоборствующей стороны, и может использоваться только на языке военных предписаний и приказов.

Неприятель : это слово используется в письменноредакционном письме .

Недруг : Используется как поэтическое слово, так и слово высокого качества.

Синонимичные и эквивалентные арабские слова для этих слов: - (عدو ، خصم ، منافس ، غريم )
Арабские слова (عدو ، خصم ، منافس، غريץ) также имеют два симантические значения, как и в предыдущих русских словах.

Слово « منافس означает то же самое, что и слово «противник» (участник спортивного матча).

Различие инструментальных значений в языках происхождения и перевода часто приводят - во время перевода - к потере этих значений. Нейтральные слова обычно заменяются на языке перевода словами, которые описаны в стиле или эмоционально окрашены на языке оригинала. Пример: -

Фармазои ! (М. Горький , Детство , гл. II)

— А Мишка твой езуит, а Яшка

В этом примере два арабских слова (منافق) и (كافر) полностью передают симантическое значение двух русских слов (езуит) и (фармазон), но они лишены качественных и эмоциональных описании (бесценное качество, негативная эмоциональная окраска) Из этих двух русских слов, которые не используются в современном русском языке.

Вопрос передачи метафорических значений слов тесно связан с вопросом передачи инструментальных значений. Метафорические выражения - с эмоциональной окраской - часто являются отправной точкой для передачи инструментальных значений.

Примеры: -

Хитер как лиса

Глуп как осел

\section{Труслив как заяц}

Такие выражения возникают, когда люди привязываются к человеческим чертам и атрибутам животных (и неживых существ), а затем к человеку.

Во всяком случае, должны быть приняты во внимание, что такие выражения не одинаковы для всех народов, и поэтому «структурная форма» таких выражений может быть разной на разных языках.

Русские выражения соответствуют полным арабским выражениям :хитер

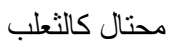

глуп как осел труслив

$$
\text { غبي كالحمار }
$$

Русское выражение (упрям как осел )не может быть переведить на арабский язык (نبد كالحمار

Концепция инструментализма He ограничивается понятием инструментального значения лингвистических единиц. Он гораздо шире, он затрагивает все вопросы, связанные с разной степенью понимания участниками процесса общения любых символов или сигналов, а также их разностороннего исследования в соответствии с опытом 
лингвистических и не лингвистических участников общения. Кажется, что неязыковой опыт - иногда называемый человеческими знаниями, культурой, опытом и предыдущей средой - в значительной степени определяет понимание участниками языковых и речивых единиц.

Общеизвестно, что человеческие знания, опыт, культура и окружающая среда прошлого, для людей с родным языком и переводом кажутся разными . В результате, то, что понятно и ясно носителям языка (оригинала), Кажется трудным или вообще непонятным для говорящих на языке, и наоборот. Конечно, переводчик не может принять это во внимание в процессе перевода. Точный перевод не может достичь своей цели, если остается непонятным для получателя, Поэтому статус инструментального фактора является необходимым условием для достижения полного соответствия перевода .

Важно отметить, что для всех типов переводческих материалов требуется - и то и другое статус инструментального фактора . , Известно, что большинство теоретиков перевода и переводчиков делят типы переводческих материалов на четыре группы в зависимости от инструментального дела :-

1- - Научные работы, ориентированные как на носителей языка(оригинала), так и на язык перевода. Степень понимания, как правило, похожа на людей, говорящих на разных языках, работающих в определенной области знаний.

2 - Статьи местной прессы и некоторые другие тексты, подготовленные для (внутреннего потребителя), но их содержание нелегко понять для читателя иностранного языка, так как он редко переводится на другие языки с статусом инструментального фактора при переводе.

3- Литературные работы, в первую очередь, для людей, которые говорят на родном языке, но часто переводятся на иностранные языки, поэтому для переводчика они представляют особые трудности с точки зрения инструментализма.

4 - материалы зарубежной политической пропаганды и декларации товаров , подготовленных к экспорту , в которых статус инструментального фактора играет значительную роль при переводе.

$$
\text { Следует отметить, что статус }
$$

инструментального фактора очень важен при переносе этих категорий от лексики, которые относятся к неэквивалентным словам, в частности, имена, географическим названиям и различным культурным и социальным коллекциям.

Известно, что все дополнения, которые включают такую информацию, должны произноситься носителями языка (оригинала), а люди, говорящие на языке перевода, не знают, - это нормальный способ перевода, цель которого - добиться полного понимания текста перевода для людей, которые говорят на языке перевода.

Наконец, в ряде случаев переводчик должен комментировать и объяснять, чтобы объяснить любую культурную и социальную работу, которая понятна носителю языка оригинала и неизвестна носителю языка перевода, в пьесе Антона Чихова (Вишневый сад) , . Например :- просит ((Ибиходов)) его обновленный ((Ты читал Покла?)). В арабском переводе этого места переводчик прокомментировал слово «Букль» в тексте Генри Томаса Букла (1821 - 1862), историка и английского социолога.

Переводчик должен улучшить использование методов перевода, упомянутых выше, чтобы сохранить оригинальность морально и методично, и всегда учитывать фактор инструментализма при переводе.

Список литературы

1- Бархударов Л. С. Язык и перевод. (Вопросы общей и частной теории перевода). М., "Междунар. отношения", 1975.

2- Большая Российская энциклопедия, 1997.

3- Голуб И.Б. Стилистика русского языка. - М., 1999.

4-

Поппер К. Логика и рост научного знания. М., 19 83

5- Розенталь Д. Э., Теленкова М. А. (Словарьсправочник лингвистических терминов) . - М, 1976.

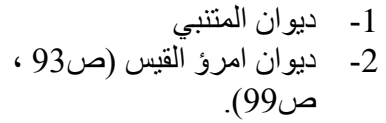

